\title{
Effects of midazolam on isoflurane minimum alveolar concentration in goats
}

\author{
T.B. Dzikiti ${ }^{\mathrm{a}, *}$, G.F. Stegmann ${ }^{\mathrm{a}}$, L.N. Dzikiti ${ }^{\mathrm{b}}$, L.J. Hellebrekers ${ }^{\mathrm{c}}$ \\ a Department of Companion Animal Clinical Studies, University of Pretoria, P. Bag X04, Onderstepoort, 0110, South Africa \\ b School of Health Systems and Public Health, University of Pretoria, Bophelo Road, Pretoria, South Africa \\ c Division of Neurophysiology and Anaesthesiology, Faculty of Veterinary Medicine, Utrecht University, P.O. Box 80.153, 3508 TD Utrecht, The Netherlands
}

\section{A R T I C L E I N F O}

\section{Article history:}

Received 7 October 2010

Received in revised form 12 January 2011

Accepted 18 January 2011

Available online xxx

\section{Keywords:}

Goat

Midazolam

Isoflurane

Minimum alveolar concentration

\begin{abstract}
A B S T R A C T
The effects of midazolam on the minimum alveolar concentration (MAC) of isoflurane in mechanically ventilated goats were evaluated. Six healthy goats ( 3 does and 3 wethers) were used in a randomized crossover design. General anaesthesia was induced with isoflurane. Endotracheal intubation was performed after which anaesthesia was maintained with isoflurane. Baseline isoflurane MAC was determined. The goats then received, on separate occasions, one of three midazolam treatments intravenously: bolus dose of $0.1 \mathrm{mg} / \mathrm{kg}$ followed by a maintenance dose of $0.1 \mathrm{mg} / \mathrm{kg} / \mathrm{h}$ (Treatment LMID), bolus dose of $0.3 \mathrm{mg} / \mathrm{kg}$ followed by a maintenance dose of $0.3 \mathrm{mg} / \mathrm{kg} / \mathrm{h}$ (Treatment MMID), bolus dose of $0.9 \mathrm{mg} / \mathrm{kg}$ followed by a maintenance dose of $0.9 \mathrm{mg} / \mathrm{kg} / \mathrm{h}$ (Treatment HMID) intravenously. Isoflurane MAC was then re-determined for each midazolam treatment. The baseline [median (inter-quartile range)] isoflurane MAC in goats was $1.40(1.38-1.41) \%$. Baseline isoflurane MAC was statistically significantly reduced $(P<0.05)$ following Treatment LMID, Treatment MMID and Treatment HMID by $16.8 \%, 35.1 \%$ and $54.7 \%$, respectively. Quality of recovery from anaesthesia was good following all midazolam treatments. Midazolam, administered by constant rate infusion, significantly reduces isoflurane MAC in goats.
\end{abstract}

(c) 2011 Elsevier B.V. All rights reserved.

\section{Introduction}

Midazolam (8-chloro-6-(2-fluorophenyl)-1-methyl4 H-imidazol $(1,5-\alpha)(1,4)$-benzodiazepine), a commonly used adjunct to general anaesthesia, has been shown to decrease anaesthetic requirements of volatile anaesthetic agents after intravenous administration in both humans and different animal species (Taira et al., 2000; Hendrickx et al., 2008). Determination of the degree of reduction of the minimum alveolar concentration (MAC) of isoflurane following administration of different dosages of midazolam may be useful in assessment of the relationship between the dosage of midazolam administered and the expected degree of reduction in isoflurane MAC.

\footnotetext{
* Corresponding author. Tel.: +27 842595508/125298282; fax: +27 125298307 .

E-mail address: brighton.dzikiti@up.ac.za (T.B. Dzikiti).
}

Isoflurane is a commonly used inhalant general anaesthetic, which has short induction and recovery times because of its low blood/gas solubility coefficient (McEwen et al., 2000). Isoflurane can be used for induction as well as maintenance of anaesthesia in goats (Antognini and Eisele, 1993). Isoflurane, like most other inhalant anaesthetic agents, causes respiratory depression, hypotension and reduced cardiac output in a dosedependent pattern (Antognini and Eisele, 1993; Hikasa et al., 2002).

By combining isoflurane with anaesthetic-sparing drugs like midazolam, potentially less isoflurane will be required to maintain general anaesthesia, and therefore the adverse cardiopulmonary effects associated with high doses of isoflurane may be minimized. We tested the null hypothesis that midazolam does not affect isoflurane MAC against the alternative hypothesis that midazolam reduces isoflurane MAC in goats. 


\section{Table 1}

Profile of the goats [median (inter-quartile range)] used in a study in which the effects of intravenously administered midazolam: $0.1 \mathrm{mg} / \mathrm{kg}$ bolus followed by continuous infusion at $0.1 \mathrm{mg} / \mathrm{kg} / \mathrm{h}$ (LMID treatment), $0.3 \mathrm{mg} / \mathrm{kg}$ bolus followed by continuous infusion at $0.3 \mathrm{mg} / \mathrm{kg} / \mathrm{h}$ (MMID treatment), or $0.9 \mathrm{mg} / \mathrm{kg}$ bolus followed by continuous infusion at $0.9 \mathrm{mg} / \mathrm{kg} / \mathrm{h}$ (HMID treatment) on the minimum alveolar concentration of isoflurane were investigated.

\begin{tabular}{|c|c|c|c|c|c|c|}
\hline \multirow[t]{2}{*}{ Treatment } & \multicolumn{6}{|l|}{ Parameter } \\
\hline & Age (months) & Weight (kg) & $\begin{array}{l}\text { Total serum } \\
\text { protein }(\mathrm{g} / \mathrm{L})\end{array}$ & Haematocrit (L/L) & $\begin{array}{l}\text { White Cell Count } \\
\left(\times 10^{9} / \mathrm{L}\right)\end{array}$ & $\begin{array}{l}\text { Rectal temperature } \\
\left({ }^{\circ} \mathrm{C}\right)\end{array}$ \\
\hline LMID & $12.0(11.3-12.8)$ & $29.7(24.1-33.6)$ & $65.2(63.3-67.7)$ & $0.37(0.32-0.40)$ & $12.72(12.3-14.30)$ & $39.2(38.9-39.3)$ \\
\hline MMID & $12.00(12.0-12.8)$ & $27.3(24.9-30.3)$ & $68.6(61.9-69.9)$ & $0.36(0.33-0.37)$ & $13.2(11.7-14.9)$ & $39.0(38.5-39.3)$ \\
\hline HMID & $12.2(11.3-12.8)$ & $28.7(23.5-31.6)$ & $67.4(63.9-70.9)$ & $0.36(0.34-0.39)$ & $12.4(11.7-13.1)$ & $39.0(38.9-39.1)$ \\
\hline
\end{tabular}

Note: no statistically significant differences $(P<0.05)$ between treatments.

\section{Materials and methods}

\subsection{General}

Six clinically healthy goats ( 3 does and 3 wethers) were used in this study. The goats were assigned to three groups with order of midazolam treatments randomized in a crossover pattern with a four-week washout period between treatments. Health status was assessed by physical examination, a complete blood count and serum biochemical analysis; all findings were normal. The profile of the goats is summarized in Table 1. Food and water were withheld for $16-22 \mathrm{~h}$ before anaesthesia. The present study was approved by both the Animal Use and Care Committee and the Research Committee of the University of Pretoria's Faculty of Veterinary Science (Research Protocol Number: V045/06).

\subsection{Instrumentation and induction of general anaesthesia}

The goats were weighed $30 \mathrm{~min}$ before the experiment. Baseline rectal temperature, heart rate and respiratory rate were recorded before the goats were placed on a custom-made sling-cum-table for easier restraint. The auricular artery on the right ear was catheterized using a 24-SWG catheter (Jelco, Medex Medical Ltd., Rossendale, Great Britain) which was then connected to a calibrated transducer (DTX Plus transducer, BD Medical, Johannesburg, South Africa) for measurement of systolic, diastolic and mean arterial blood pressures. The blood pressure readings were obtained from a calibrated electronic strain gauge transducer connected to a multi-parameter monitor (Cardiocap/5, Datex-Ohmeda Corporation, Helsinki, Finland), which had been calibrated against a mercury column within 2 months of commencement of the study. For transducer calibration to atmospheric pressure, the scapulo-humeral joint or the point of the sternum was used as zero reference points in sternally recumbent or laterally recumbent goats, respectively. An 18-SWG catheter (Jelco, Medex Medical Ltd., Rossendale, Great Britain) was introduced into the right cephalic vein for administration of intravenous fluids and midazolam.

Mask induction of the goats with isoflurane (Forane ${ }^{\circledR}$ Liquid, Abbott Laboratories Pty Ltd., Constantia Kloof, South Africa) delivered in oxygen from a circle anaesthetic breathing system with a calibrated Tec 3 out-ofcircle vaporiser (Fluotec $3^{\circledR}$, BOC Health Care, West Yorkshire, England) was achieved with the goats restrained in sternal position. Each goat was accustomed to the induction mask by initially being allowed to breathe $100 \%$ volume oxygen at $6 \mathrm{~L} / \mathrm{min}$ for at least $1 \mathrm{~min}$ before isoflurane administration rate was slowly begun with $0.5 \%$ volume increments every $15 \mathrm{~s}$ until a $3.5 \%$ volume vaporizer setting was reached. This vaporizer setting was then maintained until the jaw was relaxed enough to allow intubation. Placement of the endotracheal tube (silicone tube, internal diameter $7.5 \mathrm{~mm}$ ) was done with the goats in sternal recumbency using a laryngoscope to facilitate the process. The cuff of the endotracheal tube was inflated.

Immediately after intubation, the goats were placed in left lateral recumbency with fresh oxygen flow set at $2 \mathrm{~L} / \mathrm{min}$ and initial end-tidal (expired) isoflurane concentration targeted to be $1.6 \mathrm{vol} \%$. Intermittent positive pressure ventilation (Ohmeda 7000 Ventilator, Ohmeda, Madison, Wisconsin, USA) was used to maintain end-tidal carbon dioxide within the range of $35-45 \mathrm{mmHg}$ throughout the procedure. Ringer's lactate solution (Intramed Ringer-Lactate ${ }^{\circledR}$ Fresenius, Bodene Pty Ltd., trading as Intramed, Port Elizabeth, South Africa) was administered by a pump (Infusomat, BBraun, Melsungen, Germany) at a rate of $4 \mathrm{~mL} / \mathrm{kg} / \mathrm{h}$ intravenously.
Physiological parameters were measured using a multi-parameter monitor (Cardiocarp/5, Datex-Ohmeda Corporation, Helsinki, Finland). Three electrocardiography (ECG) electrodes were placed on shaven areas (on the middle of the left shoulder, on the midline $2 \mathrm{~cm}$ in front of the point of the sternum and on the midline $2 \mathrm{~cm}$ cranial to the tip of the xiphoid) to provide a lead II ECG tracing. Haemoglobin oxygen saturation $\left(\mathrm{SpO}_{2}\right)$ was estimated using a pulseoximetry infrared probe placed around the tongue, which calculated heart rate as well. Inspired and expired values of isoflurane, carbon dioxide and oxygen were obtained from a flow sensor and a side-stream gas sampler placed between the endotracheal tube and the Y-piece of the breathing system. The flow rate through the gas sampling line was constant at $200 \mathrm{~mL} / \mathrm{min}$. Respiratory rate was calculated from the capnogram. The gas analyzer had been calibrated with calibration gas as recommended by the manufacturer within 2 months of commencement of the studies and would automatically self-calibrate to atmospheric air at the beginning of the experiment. Temperature was measured by an oesophageal probe placed over the base of the heart. Oesophageal temperature was maintained between 37.5 and $39.5^{\circ} \mathrm{C}$ using a forced warmed air blanket and ordinary blankets placed around the goats. The physiological parameters were measured continuously during the anaesthetic period, and recorded every $15 \mathrm{~min}$.

\subsection{Baseline isoflurane MAC determination}

Determination of the baseline isoflurane (control) MAC began $15 \mathrm{~min}$ after end-tidal isoflurane values had been held constant at $1.6 \%$. The noxious stimulus used for isoflurane MAC determination was a Vulsellum forceps clamped to the second ratchet to the claw about $1 \mathrm{~cm}$ below the coronary band for $60 \mathrm{~s}$ or until occurrence of purposeful movement. Purposeful movement was strictly defined as gross movement of the head or limbs, including movement of the limb to which the Vulsellum forceps was being applied. End-tidal isoflurane value was then adjusted according to response to noxious stimulation. If no movement occurred, the end-tidal isoflurane value was reduced by a tenth (approximately $10 \%$ of end-tidal value) and held constant for at least $15 \mathrm{~min}$ before application of a noxious stimulus again. If movement was noticed, the end-tidal isoflurane value was increased by a tenth and held constant for at least $15 \mathrm{~min}$ before application of a noxious stimulus again. The four claws on the two uppermost limbs were clamped consecutively in a clockwise fashion. Isoflurane MAC was calculated as the average of two successive values; the end-tidal isoflurane value at which movement in response to noxious stimulation occurred and the preceding end-tidal isoflurane value at which movement did not occur. The isoflurane MAC was determined in duplicate and the mean of the two MACs was taken as baseline isoflurane MAC.

\subsection{Midazolam-treatment isoflurane MAC determination}

Following baseline MAC determination, the goats then received a bolus dose of midazolam administered manually over a 1 min period; at $0.1 \mathrm{mg} / \mathrm{kg}, 0.3 \mathrm{mg} / \mathrm{kg}$, or $0.9 \mathrm{mg} / \mathrm{kg}$ intravenously; followed by a maintenance dose of; $0.1 \mathrm{mg} / \mathrm{kg} / \mathrm{h}, 0.3 \mathrm{mg} / \mathrm{kg} / \mathrm{h}$, or $0.9 \mathrm{mg} / \mathrm{kg} / \mathrm{h}$ for Treatment LMID, Treatment MMID and Treatment HMID, respectively. Midazolam for maintenance of general anaesthesia was prepared up to $60 \mathrm{~mL}$ in normal saline and was administered by CRI from a $60 \mathrm{~mL}$ syringe controlled by a syringe-driving pump (Perfusor Compact, BBraun, Melsungen, Germany). The midazolam syringe was connected to the right cephalic vein catheter, to which the Ringer's Lactate administration line was also connected, by an extension tube via a three-way connection. The midazolam loading dose was administered over a period of $1 \mathrm{~min}$ and administration of the 
Table 2

Effect [median (inter-quartile range)] of intravenously administered midazolam: $0.1 \mathrm{mg} / \mathrm{kg}$ bolus followed by continuous infusion at $0.1 \mathrm{mg} / \mathrm{kg} / \mathrm{h}$ (LMID treatment), $0.3 \mathrm{mg} / \mathrm{kg}$ bolus followed by continuous infusion at $0.3 \mathrm{mg} / \mathrm{kg} / \mathrm{h}$ (MMID treatment), or $0.9 \mathrm{mg} / \mathrm{kg}$ bolus followed by continuous infusion at $0.9 \mathrm{mg} / \mathrm{kg} / \mathrm{h}$ (HMID treatment) on the minimum alveolar concentration (MAC) of isoflurane in goats.

\begin{tabular}{lll}
\hline Treatment & Isoflurane MAC (vol\%) & $\begin{array}{l}\text { Change post-treatment (\%) } \\
\text { time (min) }\end{array}$ \\
\hline Control & $1.40(1.38-1.41)^{*}$ & Not applicable \\
LMID & $1.18(1.15-1.20)^{*}$ & $-16.8(12.7-19.1)^{*}$ \\
MMID & $0.91(0.85-0.95)^{*}$ & $-35.07(29.9-40.4)^{*}$ \\
HMID & $0.65(0.63-0.68)^{*}$ & $-54.7(48.6-56.3)^{*}$ \\
\hline
\end{tabular}

* Statistically significantly different $(P<0.05)$ from all other treatments.

\# Statistically significantly different $(P<0.05)$ from LMID treatment.

maintenance dose started directly afterwards. The accuracy of delivery of midazolam by the pump was checked at the end of the experiment by calculating the expected infused amount based on infusion rates and comparing this to actual volume infused from the syringe.

Midazolam-treatment isoflurane MAC was then determined by applying a noxious stimulus with a Vulsellum forceps after every $15 \mathrm{~min}$ of end-tidal isoflurane value equilibration, and depending on the goat's response, adjusting the end-tidal isoflurane value in the same manner as described above. Response to midazolam treatment for each goat was defined as the difference between baseline and midazolam-treatment isoflurane MAC.

Since baseline isoflurane MAC was determined each time before a goat underwent one of the three midazolam treatments, the final baseline isoflurane MAC for each goat was calculated as the average of the three baseline MAC values obtained. There was no need to adjust the isoflurane end-tidal values obtained to atmospheric pressure as the gas module used for measuring respiratory gas concentrations had a sensor that constantly measured atmospheric pressure and adjusted respiratory gas readings as if they were measured at one atmospheric pressure.

\subsection{Termination of general anaesthesia}

After determination of midazolam-treatment isoflurane MAC, administration of midazolam and isoflurane was discontinued and the quality of recovery from anaesthesia of the goats observed. The endotracheal tube was removed once the goats regained the swallowing reflex.

Time to extubation, sternal position and standing were recorded. All times were determined as the interval between the time of discontinuation of midazolam and isoflurane administration and the time a particular event happened.

Quality of recovery from anaesthesia was scored on a 0-2 scale where: 0 = restlessness, 1 = relatively smooth, with some restlessness, 2 = smooth.

\subsection{Statistical analyses}

Data were analysed using the $\mathrm{R}^{\circledR}$ Statistical Software, Version 2.7.2 (The R Foundation for Statistical Computing, Vienna, Austria). All data were assumed to be non-parametric because of the small sample size and are expressed as median and inter-quartile ranges.

Data on isoflurane MAC, isoflurane MAC reduction after midazolam treatment, isoflurane MAC determination time, time to extubation, time to sternal position, time to standing, and recovery scores were tested for statistically significant differences between treatments using the Friedman test. If statistically significant differences were found between treatments, post-hoc analysis (pair-wise Wilcoxon test with a Bonferroni adjustment for multiple testing) was conducted.

Medians of repeatedly measured variables (heart rate, mean arterial blood pressure, $\mathrm{SpO}_{2}$ and body temperature) were tested for statistically significant differences between and within treatments using repeated measures analysis of variance (ANOVA) by ranks. If statistically significant differences were found, a post-hoc analysis (pair-wise Wilcoxon test with a Bonferroni adjustment for multiple testing) was conducted.

\section{Results}

\subsection{Group profile}

There were no significant differences $(P<0.05)$ in terms of median age, weight, pre-anaesthetic total serum pro- tein, haematocrit, white cell count and body temperature among the treatments (Table 1 ).

\subsection{Isoflurane MAC}

Data on observed isoflurane MAC values, changes in isoflurane MAC after treatment with midazolam and the time it took to determine isoflurane MAC are summarized in Table 2.

The baseline median minimum alveolar concentration (MAC) for isoflurane in goats was 1.40 (1.38-1.41) vol\%. This baseline median MAC was significantly greater than the median MAC values obtained after LMID treatment $(P<0.01)$, MMID treatment $(P<0.05)$, and HMID treatment $(P<0.05)$. The median isoflurane MAC values among the four groups (control and three midazolam treatments) were so different that each of the four groups had a median isoflurane MAC that was significantly different from each of the other three groups $(P<0.05)$.

The percentage reductions in isoflurane MAC after LMID treatment, MMID treatment and HMID treatment were 16.8 (12.7-19.1)\%, 35.1 (29.9-40.4)\% and 54.7 (48.6-56.3)\%, respectively. The MAC reduction percentage values were all significantly different from each other $(P<0.05)$.

The time it took to determine baseline MAC after induction of general anaesthesia was 70.0 (70.0-73.8) min (Table 2). Following midazolam bolus dose administration, time taken to determine MAC during midazolam CRI administration ranged from $67.5 \mathrm{~min}$ to $90.0 \mathrm{~min}$ for the treatment groups, and was dependent on the dose of midazolam used. The time taken to determine MAC following administration of the highest midazolam dose was significantly higher than the time it took to determine to determine MAC following administration of the lowest midazolam dose $(P<0.05)$.

\subsection{Cardiovascular effects}

The medians of cardiovascular system and respiratory system variables did not show any statistically significant differences among treatments or between the baseline reading and any subsequent points within a treatment. At all times, mean arterial blood pressure was greater than $70 \mathrm{mmHg}$ and $\mathrm{SpO}_{2}$ above $90 \%$. The end-tidal carbon dioxide partial pressure was maintained between 35 and $45 \mathrm{mmHg}$. The body temperature (Table 3 ) of the goats was maintained between 37.1 and $39.3^{\circ} \mathrm{C}$. Body temperature decreased gradually with time despite all the measures 
Table 3

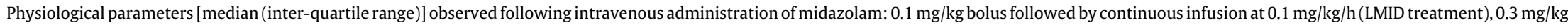
bolus followed by continuous infusion at $0.3 \mathrm{mg} / \mathrm{kg} / \mathrm{h}$ (MMID treatment), or $0.9 \mathrm{mg} / \mathrm{kg}$ bolus followed by continuous infusion at $0.9 \mathrm{mg} / \mathrm{kg} / \mathrm{h}$ (HMID treatment) in isoflurane-anaesthetised goats.

Variable Unit Treatment Time

\begin{tabular}{|c|c|c|c|c|c|c|c|c|c|c|c|c|}
\hline & & & \multirow[t]{2}{*}{ Baseline } & \multicolumn{4}{|c|}{ Period of baseline isoflurane MAC determination (min) } & \multicolumn{5}{|c|}{ Period of midazolam-treatment isoflurane MAC determination (min) } \\
\hline & & & & 2 & 15 & 30 & 45 & 2 & 15 & 30 & 45 & 60 \\
\hline \multirow{3}{*}{$\begin{array}{l}\text { Heart } \\
\text { rate }\end{array}$} & Beats/ & LMID & $84(77-106)$ & $101(89-110)$ & $93(86-107)$ & $91(86-105)$ & $94(85-103)$ & $100(90-110)$ & $99(86-111)$ & $103(87-111)$ & $106(88-114)$ & $101(87-112)$ \\
\hline & & MMID & $84(73-101)$ & $91(80-102)$ & $91(83-98)$ & $86(77-97)$ & $92(79-95)$ & $72(67-85)$ & $71(68-80)$ & $74(71-83)$ & $81(74-90)$ & 89 (77-99) \\
\hline & & HMID & $74(68-80)$ & $86(82-96)$ & $89(80-98)$ & $90(77-102)$ & $91(75-108)$ & $70(67-93)$ & $70(67-80)$ & $75(72-89)$ & $77(69-89)$ & $93(86-98)$ \\
\hline \multirow[t]{3}{*}{ SAP } & $\mathrm{mmHg}$ & LMID & $134(131-144)$ & $121(109-126)$ & $115(99-128)$ & $120(103-131)$ & $124(112-127)$ & $116(108-122)$ & $111(106-128)$ & $111(100-120)$ & $110(108-114)$ & $109(106-118)$ \\
\hline & & MMID & $117(106-123)$ & $107(101-120)$ & $105(99-112)$ & $96(93-104)$ & $100(98-100)$ & $92(89-96)$ & $94(87-98)$ & $94(85-103)$ & $94(89-103)$ & $105(99-109)$ \\
\hline & & HMID & $116(113-123)$ & $102(100-111)$ & $100(96-108)$ & $105(102-106)$ & $103(100-111)$ & $100(92-104)$ & $96(81-101)$ & $107(101-113)$ & $120(106-128)$ & $120(114-124)$ \\
\hline \multirow[t]{3}{*}{ DAP } & $\mathrm{mmHg}$ & LMID & $94(90-96)$ & $89(86-95)$ & 81 (63-99) & $86(74-104)$ & $97(80-101)$ & $92(90-94)$ & $90(84-98)$ & $88(70-93)$ & $82(80-84)$ & $87(84-89)$ \\
\hline & & MMID & $79(73-86)$ & $74(71-86)$ & $72(64-78)$ & $70(64-78)$ & $71(69-75)$ & $57(51-71)$ & $63(53-68)$ & $68(57-76)$ & $72(64-84)$ & $84(78-91)$ \\
\hline & & HMID & $81(66-92)$ & $78(69-82)$ & $75(71-77)$ & $81(79-82)$ & $82(80-87)$ & $73(66-78)$ & $67(55-72)$ & $79(69-93)$ & $96(82-99)$ & $92(88-98)$ \\
\hline \multirow[t]{3}{*}{ MAP } & $\mathrm{mmHg}$ & LMID & $115(113-116)$ & $106(96-110)$ & $96(80-111)$ & $100(88-116)$ & $111(95-112)$ & $104(93-109)$ & $99(94-113)$ & $98(84-106)$ & 97 (95-98) & $98(93-103)$ \\
\hline & & MMID & $94(88-105)$ & $84(72-99)$ & $83(78-90)$ & $80(78-88)$ & $83(81-87)$ & $70(63-79)$ & $74(66-77)$ & $78(68-87)$ & $82(78-92)$ & $93(87-100)$ \\
\hline & & HMID & $100(88-109)$ & $89(83-95)$ & $86(81-89)$ & $92(89-94)$ & $94(91-98)$ & $83(78-91)$ & $79(66-8665)$ & $91(83-102)$ & $106(87-112)$ & $105(100-110)$ \\
\hline \multirow[t]{3}{*}{$\mathrm{SpO}_{2}$} & $\%$ & LMID & - & $98(98-99)$ & 98 (97-99) & $98(96-98)$ & $97(97-98)$ & $98(97-98)$ & $98(97-98)$ & 98 (97-99) & $97(96-98)$ & $98(96-98)$ \\
\hline & & MMID & _- & 99 (98-99) & 99 (98-99) & 98 (96-99) & 99 (98-99) & 98 (97-98) & 99 (98-99) & 98 (97-99) & $98(96-98)$ & 97 (96-98) \\
\hline & & HMID & - & $98(97-98)$ & $98(98-98)$ & $98(97-98)$ & $98(97-98)$ & $97(96-98)$ & $99(96-99)$ & 98 (96-99) & $97(95-98)$ & $95(94-97)$ \\
\hline
\end{tabular}

$\mathrm{PE}^{\prime} \mathrm{CO}_{2} \quad \mathrm{mmHg} \quad \mathrm{LMID} \quad-$

38.1 (33.8-34.5) $35.2(33.9-37.1) \quad 35.3(34.1-36.4) \quad 34.9$ (33.9-39.8) $35.3(34.7-37.5) \quad 36.0(33.9-40.9) 36.4(34.7-39.2) 37.5(36.2-41.1) 36.8(36.2-39.0)$ $38.0(34.6-43.7) 37.6(32.7-41.4) \quad 36.9(35.0-39.3) 35.7(35.2-38.6) 36.1(35.0-37.8) 35.0(35.0-35.0) 35.0(35.0-40.1) 34.6(34.2-35.5) 35.3(35.0-36.3)$ 35.7 (35.2-40.9) $35.0(34.4-37.2) \quad 36.5$ (34.6-37.8) 35.3 (35.0-35.7) 36.5 (35.8-41.2) $35.7(35.2-36.9) 35.0(34.4-35.5) 34.2(33.6-40.5) 39.9(38.0-43.5)$

Temp $\quad\left({ }^{\circ} \mathrm{C}\right) \quad$ LMID $\quad 39.2(38.9-39.3) \quad 38.6(38.4-38.9) \quad 38.3(38.2-38.4) \quad 38.1(37.9-38.4) 38.1(37.8-38.2) \quad 38.0(37.9-38.1) 38.0(37.9-38.0 *)^{*} 37.8(37.6-37.9)^{*} 37.8(37.5-37.8)^{*} 37.7(37.4-37.9)$ MMID $\quad 39.0(38.8-39.3) \quad 38.3(38.2-38.5) \quad 38.3(38.2-38.5) \quad 38.2(38.0-38.3) \quad 38.2(38.1-38.6) \quad 38.2(37.6-38.5) \quad 38.1(37.8-38.4) \quad 38.1(37.7-38.5) \quad 38.1(37.6-38.4) \quad 37.4(37.5-38.3)$ HMID $\quad 39.0(38.9-39.1) 38.3(38.2-38.6) \quad 38.4(38.2-38.5) \quad 38.0(37.7-38.2) \quad 37.9(37.7-37.9) \quad 37.7(37.6-37.9) \quad 37.6(37.4-37.8)^{*} 37.3(37.1-37.7)^{*} 37.2(37.1-37.7)^{*} 38.3(37.2-37.9)$

SAP: systolic arterial pressure; DAP: diastolic arterial pressure; $\mathrm{MAP}$ : mean arterial pressure; $\mathrm{SpO}_{2}$ : saturation of haemoglobin with oxygen in peripheral blood; $\mathrm{PE}^{\prime} \mathrm{CO}_{2}$ : end-tidal carbon dioxide partial pressure Temp: body temperature.

"Statistically significantly different $(P<0.05)$ from baseline reading within group. 
Table 4

Quality of recovery from anaesthesia [median (inter-quartile range)] observed in a study where the effects of intravenously administered midazolam: $0.1 \mathrm{mg} / \mathrm{kg}$ bolus followed by continuous infusion at $0.1 \mathrm{mg} / \mathrm{kg} / \mathrm{h}$ (LMID treatment), $0.3 \mathrm{mg} / \mathrm{kg}$ bolus followed by continuous infusion at $0.3 \mathrm{mg} / \mathrm{kg} / \mathrm{h}$ ( $\mathrm{MMID}$ treatment), or $0.9 \mathrm{mg} / \mathrm{kg}$ bolus followed by continuous infusion at $0.9 \mathrm{mg} / \mathrm{kg} / \mathrm{h}$ (HMID treatment) on the minimum alveolar concentration of isoflurane in goats were investigated.

\begin{tabular}{llll}
\hline Treatment & $\begin{array}{l}\text { Time to extubation } \\
\text { (min) }\end{array}$ & $\begin{array}{l}\text { Time to sternal } \\
\text { position (min) }\end{array}$ & \multicolumn{1}{c}{$\begin{array}{l}\text { Time to standing } \\
\text { (min) }\end{array}$} \\
\hline sMID & $3.0(2.3-3.0)$ & $4.0(1.5-5.0)$ & $12.5(10.0-15.0)$ \\
MMID & $3.0(2.3-4.5)$ & $3.0(1.5-4.5)$ & $13.5(10.5-18.8)$ \\
HMID & $5.0(2.8-5.0)$ & $5.0(1.5-7.0)$ & $2(2-2)$ \\
\hline
\end{tabular}

Note: no statistically significant differences $(P<0.05)$ between any groups.

that were taken to conserve and supplement body heat in the goats. The body temperature readings observed in two groups onwards of 15 min from commencement of midazolam treatment were statistically significantly lower than baseline observations, but were still within physiologically acceptable limits.

\subsection{Recovery from general anaesthesia}

The quality of recovery from anaesthesia (Table 4) was good for all the three treatments and there were no differences among groups.

\section{Discussion}

The observed median isoflurane MAC of $1.40 \mathrm{vol} \%$ in the present study is comparable to observations from other studies in which a noxious stimulus was used to determine MAC (Antognini and Eisele, 1993; Hikasa et al., 1998, 2002; McEwen et al., 2000; Doherty et al., 2002a,b, 2004). In the present study, isoflurane MAC was defined according to Merkel and Eger (1963), as the lowest isoflurane alveolar (end-tidal) concentration required by an individual goat to prevent gross purposeful movement in response to a supramaximal stimulus, which in the present study was claw-clamping using a Vulsellum forceps. In the present study, isoflurane MAC determination was begun $15 \mathrm{~min}$ after induction, whereas most previous studies on effects of drugs on inhalation agent MAC allowed a waiting period of $1 \mathrm{~h}$ before beginning determination of the MAC (Doherty et al., 2002a,b). The short waiting period before beginning determination of MAC of the present study could mean that there was relatively poor equilibration of isoflurane among body tissues which could have influenced the MAC values obtained. The outcomes of the present study show very little variability among the baseline isoflurane MAC despite early commencement of MAC determination.

The median percentage reductions in isoflurane MAC of $16.8 \%, 35.1 \%$ and $54.7 \%$ following administration of Treatment LMID, Treatment MMID and Treatment HMID, respectively, show a substantial and dose-dependent effect. There is no previous study focusing specifically on the effects of midazolam on isoflurane MAC in goats or other animal species; but, in humans, administration of low dose midazolam (bolus at $0.1 \mathrm{mg} / \mathrm{kg}$ followed by $0.06 \mathrm{mg} / \mathrm{kg} / \mathrm{h}$ maintenance dose), moderate dose midazolam (bolus at $0.2 \mathrm{mg} / \mathrm{kg}$ followed by $0.12 \mathrm{mg} / \mathrm{kg} / \mathrm{h}$ maintenance dose), high dose midazolam (bolus at $0.4 \mathrm{mg} / \mathrm{kg}$ followed by $0.24 \mathrm{mg} / \mathrm{kg} / \mathrm{h}$ mainte- nance dose) reduced halothane MAC by $40 \%, 50 \%$ and $70 \%$, respectively (Inagaki et al., 1993). This comparison shows that midazolam produces marked reductions in inhalation anaesthetic requirements for general anaesthesia in both humans and goats, with a more pronounced reduction in humans. Stegmann and Bester (2001) concluded that the sedative and hypnotic effects of intravenously administered midazolam were dose-dependent. The dosages of midazolam used in the present study are based on those of other species and are not based on pharmacokinetic data for goats since this kind of data is presently unavailable (Hall et al., 1988; Inagaki et al., 1993). In retrospect, the loading dose of midazolam should have been administered over a longer period, and not just $1 \mathrm{~min}$ as done in the present study. A time longer than $15 \mathrm{~min}$ should also have been allowed before beginning of determination of isoflurane MAC during the period of midazolam treatment. Previous studies on effects of drugs on inhalation agent MAC allowed a waiting period of about $45 \mathrm{~min}-1 \mathrm{~h}$ before beginning determination of the MAC (Hall et al., 1988; Doherty et al., 2002a,b). The value of the present study could have been greatly improved if the plasma concentration of midazolam had been determined as this would have ascertained whether steady state had been reached at the time of isoflurane MAC determination during midazolam CRI.

The magnitude of reduction of isoflurane MAC following midazolam administration shows that midazolam has a significant role to play as an adjunct to balanced anaesthesia in goats. The reduction in isoflurane requirements for maintaining general anaesthesia is important as use of less isoflurane will obtund isoflurane-related adverse effects (Hikasa et al., 2002; Dzikiti et al., 2003). The common adverse effects associated with isoflurane include respiratory depression, hypotension and reduced cardiac output (Antognini and Eisele, 1993; Hikasa et al., 2002). Using less isoflurane also has the advantage of reducing the hazard of atmospheric pollution, and thus reducing environmental exposure to isoflurane and its metabolic products (Joubert, 1999). Both midazolam and isoflurane have been reported, though without full confidence for isoflurane, to produce central nervous system depression by potentiating the gamma-aminobutyric (GABA) receptor-channel complex (Larsen et al., 1998; Tatsuo et al., 1999). Midazolam probably reduces isoflurane MAC in an additive or synergistic manner through its activities at GABA receptor complex (Hendrickx et al., 2008).

Cardiovascular function was minimally affected following administration of midazolam to isoflurane anaes- 
thetised goats in the present study. The mean arterial blood pressure and $\mathrm{SpO}_{2}$ obtained even after administration of the highest dose of midazolam in this study were within normal physiological limits and were similar to baseline values within a group. It is well documented in literature that midazolam, especially when used alone does not cause significant changes on cardiopulmonary function (Mehlisch, 2002; Dzikiti et al., 2009). It is important to maintain body temperature, blood pressure and tissue oxygenation within normal physiological limits as was done in the present study because hypothermia, severe hypotension and hypoxaemia are all known to reduce isoflurane MAC (Eger, 2002). Although the body temperature of the goats in this study steadily decreased to a lowest reading of $37.2^{\circ} \mathrm{C}$ with time, this value still falls within normal ranges reported in healthy, non-anaesthetised goats in which values as low as $37.2^{\circ} \mathrm{C}$ have been reported (Ayo et al., 1998).

The quality of recovery from anaesthesia was good in all groups. Administration of midazolam as an adjunct to isoflurane for maintenance of general anaesthesia did not substantially prolong time to removal of the endotracheal tube, time to attainment of sternal position or time to standing. The short recovery periods show that the interaction between midazolam and isoflurane does not significantly prolong recovery time.

\section{Conclusions}

Intravenously administered midazolam is able to decrease isoflurane MAC in a dose-dependent manner. Cardiovascular function was not substantially affected by administration of midazolam. This study shows that intravenous administration of midazolam significantly reduces isoflurane requirements for maintenance of general anaesthesia without significantly affecting cardiovascular function in goats.

\section{Acknowledgements}

This study was jointly funded by the University of Pretoria, the South African Veterinary Foundation (SAVF) - laboratory costs, Fresenius Kabi South Africa - Ringer Lactate and the University of Pretoria - Utrecht University Memorandum of Understanding (UP-UU) MSc/PhD Research Fund - purchase and upkeep of the goats. Gratitude is expressed to Ms Lebo Sentle and Monicca Ngobeni of the University of Pretoria Biomedical Centre who worked tirelessly offering technical support to the research.

\section{References}

Antognini, J.F., Eisele, P.H., 1993. Anaesthetic potency and cardiopulmonary effects of enflurane, halothane, and isoflurane in goats. Lab. Anim. Sci. 43, 607-610.

Ayo, J.O., Oladele, S.B., Ngam, S., Fayon, S., Afolayan, S.B., 1998. Diurnal fluctuations in rectal temperature of the Red Sokoto goat during the harmattan season. Res. Vet. Sci. 66, 7-9.

Doherty, T.J., Rohrbach, B.W., Geiser, D.R., 2002a. Effect of acepromazine and butorphanol on isoflurane minimum alveolar concentration in goats. J. Vet. Pharmacol. Ther. 25, 65-67.

Doherty, T.J., Rohrbach, B.W., Ross, L., Schultz, H., 2002b. The effect of tiletamine and zolazepam on isoflurane minimum alveolar concentration in goats. J. Vet. Pharmacol. Ther. 25, 233-235.

Doherty, T.J., Will, W.A., Rohrbach, B.W., Geiser, D.R., 2004. Effect of morphine and flunixine meglumine on isoflurane minimum alveolar concentration in goats. Vet. Anaesth. Analg. 31, 97-101.

Dzikiti, T.B., Hellebrekers, L.J., van Dijk, P., 2003. Effects of intravenous lidocaine on isoflurane concentration, physiological parameters, metabolic parameters and stress-related hormones in horses undergoing surgery. J. Vet. Med. A Physiol. Pathol. Clin. Med. 50, 190-195.

Dzikiti, T.B., Stegmann, G.F., Hellebrekers, L.J., Auer, R.E.J., Dzikiti, L.N., 2009. Sedative and cardiopulmonary effects of acepromazine, midazolam, acepromazine-butorphanol and midazolam-butorphanol on propofol anaesthesia in goats. J. S. Afr. Vet. Assoc. 80, 10-16.

Eger II, E.I., 2002. A brief history of the origin of minimum alveolar concentration (MAC). Anaesthesia 96, 238-239.

Hall, R.I., Schwieger, I.M., Hugg Jr., C.C., 1988. The anesthetic efficacy of midazolam in the enflurane-anesthetized dog. Anesthesiology 68, 862-868.

Hendrickx, J.F.A., Eger II, E.I., Sonner, J.M., Schafer, S.L., 2008. Is synergy the rule: a review of anaesthetic interactions producing hypnosis and immobility. Anesth. Analg. 107, 494-506.

Hikasa, Y., Hokushini, S., Takase, K., Ogasawara, S., 2002. Cardiopulmonary, haematological, serum biochemical and behavioural effects of sevoflurane compared with isofurane or halothane in spontaneously ventilating goats. Small Rum. Res. 43, 167-178.

Hikasa, Y., Okuyama, K., Kakuta, T., Takase, K., Ogasawara, S., 1998. Anesthetic potency and cardiopulmonary effects of sevoflurane in goats: comparison with isoflurane and halothane. Can. J. Vet. Res. 62, 299-306.

Inagaki, Y., Sumikawa, K., Yoshiya, I., 1993. Anesthetic interaction between midazolam and halothane in humans. Anesth. Analg. 76, 613-617.

Joubert, K., 1999. The hidden dangers of anaesthestic machines. J. S. Afr. Vet. Assoc. 70, 140-141.

Larsen, M., Haugstad, T.S., Berg-Johnsen, J., Langmoen, I.A., 1998. Effect of isoflurane on release and uptake of $\gamma$-aminobutyric acid from rat cortical synaptosomes. Br. J. Anaesth. 80, 634-638.

McEwen, M.M., Gleed, R.D., Ludders, J.W., Stokol, T., Del Piero, F., Erb, H.N., 2000. Hepatic effects of halothane and isoflurane anaesthesia in goats. J. Am. Vet. Med. Assoc. 217, 1697-1700.

Mehlisch, D.R., 2002. The efficacy of combination analgesic therapy in relieving dental pain. J. Am. Dent. Assoc. 133, 861-871.

Merkel, G.M., Eger II, E.I., 1963. A comparative study of halothane and halopropane anesthesia including method for determining equipotency. Anesthesiology 24, 346-357.

Stegmann, G.F., Bester, L., 2001. Sedative-hypnotic effects of midazolam in goats after intravenous and intramuscular administration. Vet. Anaesth. Analg. 28, 49-55.

Tatsuo, M.K.A.F., Salgado, J.V., Yokoro, C.M., Duarte, I.D.G., Francischi, J.N., 1999. Midazolam-induced hyperalgesia in rats: modulation via $G_{A B A}$ receptors at supraspinal level. Eur. J. Pharmacol. 370, 9-15.

Taira, Y., Nakakimura, K., Matsumoto, M., Sakabe, T., 2000. Spinal and supraspinal midazolam potentiates antinociceptive effects of isoflurane. Br. J. Anaesth. 85, 881-886. 